\title{
The knowledge level of dental students on color stability composite resin restoration in the COVID-19 pandemic era
}

\author{
Chaterina Anjelia ${ }^{1}$, Octarina ${ }^{2}$ \\ ${ }^{1}$ Faculty of Dentistry Universitas Trisakti, Jakarta, Indonesia \\ ${ }^{2}$ Departement of Dental Material, Faculty of Dentistry, Universitas Trisakti, Jakarta, Indonesia
}

\author{
Article Info \\ Article history: \\ Received May 30, 2021 \\ Revised Aug 16, 2021 \\ Accepted Aug 25, 2021

\section{Keywords:} \\ The level of knowledge \\ Dental material \\ Composite resin \\ Color stability \\ COVID-19 pandemic
}

\begin{abstract}
During the COVID-19 pandemic in Indonesia, all professional program students learning online and still expected to have good knowledge including dental materials. Color stability of anterior teeth restoration is the most important thing. Professional program students with a good level of knowledge were expected to support the use of composite resin towards patients without causing discoloration. The aim of this study was to assess the knowledge level of professional program students towards color stability of composite resin restoration in the Faculty of Dentistry, Universitas Trisakti in the COVID-19 pandemic era. This was a descriptive observational study using a cross-sectional approach. Data were collected using Google Form with a questionnaire that had been tested for validity and reliability. The sample was 100 professional program students who met the inclusion criteria and accepted informed consent. This study found that in the COVID19 pandemic era, the knowledge level of 49 respondents (49\%) was good, 37 respondents $(37 \%)$ were fairly good and 14 respondents (14\%) were less good. The majority of the professional program students of the Faculty of Dentistry, Universitas Trisakti were in the good category of knowledge about the color stability of composite resin restoration.
\end{abstract}

This is an open access article under the CC BY-SA license.

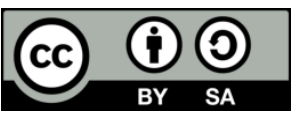

Corresponding Author:

Octarina

Department of Dental Material

Faculty of Dentistry

Universitas Trisakti

Jakarta 11440, Indonesia

Email: octarina@trisakti.ac.id

\section{INTRODUCTION}

In the era of the COVID-19 pandemic, all Indonesian students study online. However, professional program students still need to have good knowledge of dental materials. Because dentistry material is a basic knowledge that students must have before doing treatment by applying the material to patients. Knowledge of the color stability of composite resins is important, especially during a pandemic, online learning methods are the best choice; students only learn theory without doing offline practice [1]. However, the online learning method has advantages and disadvantages [2], [3]. Dental students are expected to be more aware of this. Because if they do not pay attention to this it will cause a lack of knowledge. Especially regarding the color stability of the composite resin so that it will cause the results of the composite resin application that are not optimal, especially in terms of aesthetics.

Composite resin can provide the best aesthetic tooth-colored restoration. This causes the composite resin to be used frequently and its use is increasing every year [4], [5]. Studies have shown that composite 
resins are most used for anterior teeth [6]. The composite resin restoration must have good color stability to maintain aesthetic qualities. The color stability of the composite resin is influenced by various factors [7]. The resin matrix has properties that can absorb the liquid. The water absorption that happens causes the composite resin to change color [8]. The higher amount of filler results in better color stability of the composite resin [9]. Finishing and polishing procedures are important to maintain the aesthetic quality of a composite resin restoration [10]. Aluminum oxide coated abrasive discs is one of the instruments that are often used because based on several studies it is considered effective for finishing and polishing [11]. Polishing that delayed up to 24 hours resulted in less discoloration compared with immediately after the restoration. This statement is related to the composite resin polymerization process that lasts for 24 hours [12]. The restoration that has the oxygen-inhibited layer will increase the color change. The oral cavity environment affects the color stability of the composite resin [13].

Professional program students are practitioners who have a direct role in the dental and oral health sector. Treatment of problems such as caries in the anterior teeth can be treated using composite resins [6]. However, the color of the composite resins may change along with its use. The discoloration of the composite resin restoration will highly affect aesthetic factors, especially in the anterior teeth. Thus, professional program students are expected to have a good level of knowledge and support the use of composite resins with good color stability even in the COVID-19 pandemic era.

\section{RESEARCH METHOD}

This type of research was descriptive observational with a cross-sectional design. Sample was selected with purposive sampling technique and determination of the number of samples using a descriptive categorical formula. The sample in this study was students of the professional program in the Faculty of Dentistry, Universitas Trisakti who had worked on the resin composite restoration. This study has been declared to have passed the ethical test with research no. 357/S1/KEPK/FKG/7/2020.

The data were processed using SPSS. The validity testing of the questionnaire used the Pearson Correlation. Questionnaire questions are declared valid if the $r$ count is greater than the $r$ table with a significance level of 5\% [14]. The reliability testing of the questionnaire used Cronbach's Alpha (0.740). This study used a questionnaire containing 15 multiple choice questions. The questionnaire in this study contains factors that affect color stability such as compositions of composite resin and the finishing-polishing procedure.

This research was done in September 2020 through an online questionnaire distributed via Google Form. A total of 100 respondents filled out the questionnaire after agreeing upon informed consent. The results of this study are in the form of an assessment on student knowledge which will be discussed based on their level of knowledge. The level of knowledge consists of knowing, comprehension, application, analysis, synthesis, and evaluation [15].

\section{RESULTS AND DISCUSSION}

During the pandemic, learning using the online method is the best choice and demand for all students [1]. Each learning method has its advantages and disadvantages. Online learning methods have advantages such as saving in terms of time and energy, more flexibility, ease of access, and obtaining additional learning materials from anywhere. So that dental students are expected to be able to carry out the learning process optimally during the pandemic. But there are some disadvantages such as must have a supporting technology device, stable internet, sometimes not optimal delivery of learning material which is influenced by many factors and decreased student concentration due to too long learning time and lack of motivation in online learning [2], [3].

To the best of our knowledge, this is the first dental materials questionnaire that discusses the color stability of composite resin restoration conducted on dental students. In this study, we realized that there were limitations. Because the research was conducted during a pandemic, there was limited to using the google form with small sample size and was limited to the Faculty of Dentistry, Universitas Trisakti. Despite these limitations, our results have important implications, because the findings can provide baseline data about the knowledge level of dental students regarding the color stability of composite resin restoration. This research was conducted online via Google Form with a total of 100 respondents as shown in Table 1. Table 2 shows data on the level of professional semesters that are being undertaken by respondents in this study.

Table 1. Respondent characteristics

\begin{tabular}{lcc}
\hline Gender & Frequency (n) & Percentage (\%) \\
\hline Male & 22 & $22 \%$ \\
Female & 78 & $78 \%$ \\
Total & 100 & $100 \%$ \\
\hline
\end{tabular}

Int. J. Public Health Sci., Vol. 10, No. 4, December 2021: $751-757$ 
Table 2. Respondent's level of professional semester

\begin{tabular}{ccc}
\hline Level of the professional semester & Frequency (n) & Percentage (\%) \\
\hline Semester 1 & 0 & 0 \\
Semester 2 & 1 & $1 \%$ \\
Semester 3 & 55 & $55 \%$ \\
Semester 4 & 14 & $14 \%$ \\
Above semester 4 & 30 & $30 \%$ \\
Total & 100 & $100 \%$ \\
\hline
\end{tabular}

There are the results of the answers from all respondents who filled out the questions on this questionnaire. Almost all questions can be answered correctly by the respondents, but there are some questions that can only be answered by some respondents as shown in Table 3 (see in Appendix). Color stability is the ability of the composite resin filler to maintain the color from the beginning until the end [16]. Almost all respondents (80\%) could answer the question correctly because knowledge at the initial level (knowing) about color stability of composite resin restoration has been obtained by professional program students while taking the dentistry study program.

The resin and filler matrix are intrinsic factors that play an important role in maintaining the color stability of the composite resin restoration [7]. The resin matrix with the urethane dimethacrylate (UDMA) monomer type has better color stability. This is because the UDMA monomer absorbs less water than bisphenol-A glycidylmethacrylate (Bis-GMA) [9], [17]. Fillers with smaller sizes and other larger fillers will produce good color stability [9], [18]. There were 80 respondents (80\%) who answered the question correctly because students already have knowledge at the comprehension level and have obtained materials on this topic during undergraduate studies and while undertaking the professional program as well.

The resin matrix monomers are hydrophilic and contain hydroxyl groups that form bonds with water molecules. This makes the resin matrix monomers absorb the liquid around them and increase the color change in the composite resin restoration [8], [18]. Only 55 respondents (55\%) answered the question correctly because professional program students had not yet had knowledge regarding resin matrix monomers at the comprehension level. This was because students only receive the materials passively during lectures without seeking further information about the composition of the resin matrix monomers. During a pandemic, dental students must have a high level of awareness. If the dental student's level of knowledge is still lacking, it is expected to find out and learn more independently.

The type of filler contained in the nanocomposite resin is nanoparticle-sized and can fill the gaps between larger particles so that water absorption is reduced [19]. Almost all respondents (83\%) could answer the question correctly because students already have knowledge at the initial level (knowing). The question is general knowledge so that most of the students could answer correctly without having to seek additional materials regarding the type of composite resin that has good color stability.

A small filler of composite resin will produce better color stability because it increases the density between particles. This causes the composite resin to have a smooth surface, no holes, and is easy to polish [19]. There were 84 respondents (84\%) who answered the question correctly because students already have knowledge at the comprehension level. Materials on the effect of small size fillers were obtained during undergraduate studies. Students have also deepened their knowledge so that they could understand the role of small size fillers and could answer the question correctly.

The color change is less in the smooth surface composite resin samples. This is because the smooth restoration surface will minimize the forming of stains and plaque [17]. Almost all respondents (91\%) could answer the question correctly because students already have knowledge at the initial level (knowing). They have obtained general materials about a good surface for color stability of the restoration during lectures.

Finishing is a procedure of reducing, adjusting, and shaping to obtain a restoration with a shape that matches the anatomy of natural teeth [20]. The results showed that 82 respondents $(82 \%)$ answered the question correctly and 18 respondents (18\%) answered incorrectly. Polishing is a procedure to reduce the roughness caused by the instrument during the finishing process. Therefore, the restoration will have a smooth and glossy surface [17], [20]. The results showed that 88 respondents (88\%) could answer the question correctly and 12 respondents (12\%) answered incorrectly. Students could answer both questions about the understanding of finishing and polishing procedures because they have knowledge at the initial level (knowing). The understanding of the two procedures is the basic material that has been obtained during undergraduate studies.

The finishing procedure stage is carried out in order from coarse to fine with the aim of evenly spreading the scratches and eroding the resin matrix and filler particles evenly [20], [21]. In line with this statement, the finishing procedure begins with shaping (reduction of excess restoration), contouring (anatomy forming), and ends with pre-polishing (surface smoothing) [22]. There were 78 respondents (78\%) who could answer the question correctly because students already have knowledge at the application level. Students

The knowledge level of dental students on color stability composite resin restoration... (Chaterina Anjelia) 
were looking for additional information independently so that they could answer the question correctly about good stages in carrying out the finishing procedure. Aluminum oxide-coated abrasive discs can produce a flat and smooth filling surface, especially for anterior tooth composite resin restoration [23]-[25]. The results showed that 74 respondents $(74 \%)$ could answer the questions correctly, indicating that students already have knowledge at the initial level (knowing) about the instruments used for finishing and polishing. Information about finishing and polishing instruments has been obtained by the students during undergraduate studies or when carrying out the professional program.

Several studies have shown that composite resin restoration with a delayed polishing procedure for 24 hours results in good color stability [12], [26], [27]. This study is in line with the theory regarding the polymerization process of composite resin which lasts for 24 hours. Only 52 respondents (52\%) answered the question correctly because students had not yet had knowledge at the application level. This occurred because students only got information about the correct polishing time passively during lectures and did not seek additional information, thus could not answer the question correctly. The surface of the composite resin that has an oxygen-inhibited layer will have a lower degree of polymerization which will increase the color change [13], [28]. Only 43 respondents (43\%) answered the question correctly because professional program students had not yet had knowledge in the analysis level regarding the role of the oxygen-inhibited layer on composite resin embedding. Students only received material during lectures without deepening or seeking more information about the role of the oxygen-inhibited layer.

Color stability of the composite resin restoration is influenced by the oral environment [29]. The color change is higher in the soaking beverage with the lowest $\mathrm{pH}$. This occurs because low $\mathrm{pH}$ can damage the resin matrix so that water absorption and discoloration will increase [30]. Only 52 respondents (52\%) answered the question correctly because professional program students only had knowledge at the initial level (knowing). Therefore, they could not answer the question regarding $\mathrm{pH}$ in the oral cavity reducing color stability at the analysis level. The dye in the drinks penetrates the surface of the restoration and will diffuse into the composite resin [31]. Almost all respondents (91\%) could answer correctly. This shows that students had knowledge at the initial level (knowing) about the effect of colored drinks on composite resin restoration. Students in general will be able to answer the question without the need to seek or deepen their knowledge regarding the role of colored drinks.

Alcohol molecules contained in the drink will be absorbed by the resin matrix so that it will cause material degradation and increase the roughness of the surface of the composite resin restoration [32]. The results showed that 71 respondents $(71 \%)$ answered the question correctly because students already had knowledge about the effect of alcoholic beverages on the color stability of the composite resin restoration at the analysis level. Students actively increased their knowledge, thus could correctly answer the question about the role of alcohol molecules on the restoration surface at the analysis level.

Results of each respondent were added up and divided by the number of questions (15), then were displayed in percentages. After that, they were grouped into three levels, namely good if answering $76 \%$ $100 \%$ correctly, fairly if answering correctly $56 \%-75 \%$, and less if answering correctly $\leq 55 \%$. Based on the results of the data obtained, it was found that the level of knowledge at COVID-19 pandemic era was 49 respondents (49\%) were at a good level, 37 respondents (37\%) were at a fairly good level, and 14 respondents $(14 \%)$ were at a less good level as presented in Figure 1.

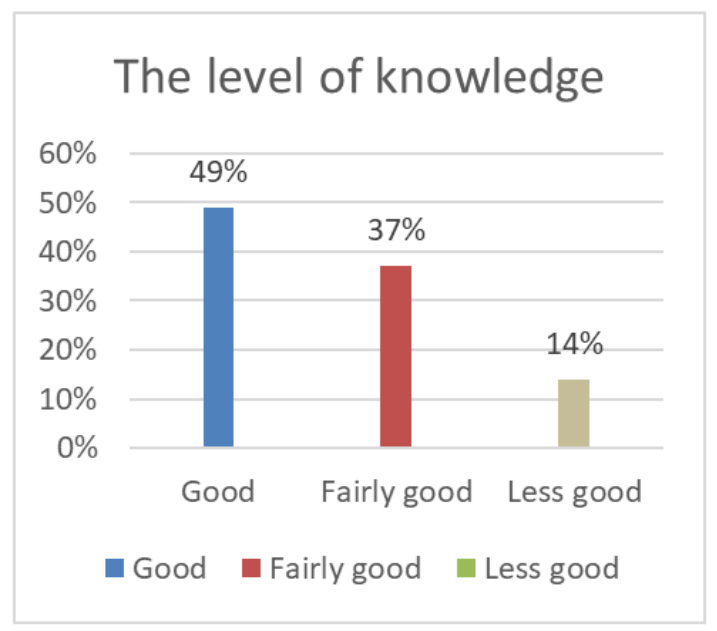

Figure 1. Distribution diagram of the level of knowledge of professional program students 
From the result of all data obtained the knowledge level of professional program students on color stability composite resin restoration was at a good level even in the COVID-19 pandemic era. But, here some questions that had some less good results. However, students are expected to improve and increase their knowledge about color stability. To increase the effectiveness of independent online learning during the pandemic, it is expected that dental students can provide stable internet, comfortable study rooms, manage their time as well as possible, and evaluations. Motivation to learn online during the pandemic must be maintained and increased. Motivation must come from dental students and can be supported by a supportive environment. Dental students can find a good learning environment such as conducting discussions related to learning [3], [33], [34].

Dental students are expected to find effective learning methods. Most methods of learning to read like looking for additional materials about the color stability of the composite resin restoration independently through textbooks, the internet, journals, and dentistry magazines. If students feel bored with the reading learning method, it is advisable to change the learning method. For example, learn through video, or group discussion, because learning is not only in reading. Dental students can learn from clinical skills demonstrations and recorded videos of the laboratory. Attending an online seminar because during the pandemic it is easier to access. Group discussion is also one of the things that can increase knowledge and motivation in learning [1], [3], [34].

\section{CONCLUSION}

The level of knowledge of dental students on the color stability of composite resin restorations is important because it is a basic science for clinical applications in dental patients. Based on the results of the research and discussion, it can be concluded that the level of knowledge regarding the color stability of the composite resin restoration of the professional program students of the Faculty of Dentistry, Universitas Trisakti is in a good category (49\%). This study can be used as a preliminary study to conduct further study models to obtain more comprehensive results.

\section{ACKNOWLEDGEMENTS}

The authors would like to thank all respondents and the RSGM-P Faculty of Dentistry Universitas Trisakti for providing support in research.

\section{REFERENCES}

[1] M. Agius et al., "Self-reported dental student stressors and experiences during the COVID-19 pandemic," J. Dent. Educ., vol. 85, no. 2, pp. 208-215, 2021, doi: 10.1002/jdd.12409.

[2] D. Pandey and P. S. Sharma, "Distance Learning in Higher Education during Pandemic: Challenges and Opportunities Management of Technology Enhanced Learning in Higher Education: A Study from Students Perspective in Chhattisgarh View project," Artic. Int. J. Indian Psychol., vol. 8, no. 2, pp. 25-28, 2020, doi: 10.25215/0802.204.

[3] K. Mukhtar, K. Javed, M. Arooj, and A. Sethi, "Advantages, limitations and recommendations for online learning during covid-19 pandemic era," Pakistan J. Med. Sci., vol. 36, no. COVID19-S4, pp. S27-S31, 2020, doi: 10.12669/pjms.36.COVID19-S4.2785.

[4] R. Yadav and M. Kumar, "Dental restorative composite materials: A review," J. Oral Biosci., vol. 61, no. 2, pp. 78-83, 2019, doi: 10.1016/j.job.2019.04.001.

[5] S. Ardu, O. Duc, E. Di Bella, I. Krejci, and R. Daher, "Color Stability of Different Composite Resins After Polishing," Odontology, vol. 106, no. 3, pp. 328-333, 2018, doi: 10.1007/s10266-017-0337-y.

[6] K. H. S. Chan, Y. Mai, H. Kim, K. C. T. Tong, D. Ng, and J. C. M. Hsiao, "Review: Resin composite filling," Materials (Basel)., vol. 3, no. 2, pp. 1228-1243, 2010, doi: 10.3390/ma3021228.

[7] A. Menon, D. M. Ganapathy, and A. V. Mallikarjuna, "Factors that influence the colour stability of composite resins," Drug Invent. Today, vol. 11, no. 3, pp. 744-749, 2019.

[8] L. S. Cortopassi, C. A. K. Shimokawa, A. E. Willers, and M. A. P. Sobral, "Surface Roughness and Color Stability of Surface Sealants and Adhesive Systems Applied Over a Resin-based Composite," Journal of Esthetic and Restorative Dentistry, vol. 32, no. 1. pp. 64-72, 2020, doi: 10.1111/jerd.12548.

[9] U. Erdemir, E. Yıldiz, and M. Mert, "Effects of sports drinks on color stability of nanofilled and microhybrid composites after long-term immersion," J. Dent., vol. 40, no. 2012, pp. e55-e63, 2020, doi: 10.1016/j.jdent.2012.06.002.

[10] E. Yildiz, E. Sirin Karaarslan, M. Simsek, A. S. Ozsevik, and A. Usumez, "Color stability and surface roughness of polished anterior restorative materials,” Dent. Mater. J., vol. 34, no. 5, pp. 629-639, 2015, doi: 10.4012/dmj.2014344.

The knowledge level of dental students on color stability composite resin restoration... (Chaterina Anjelia) 
[11] E. Eden, D. Cogulu, and T. Attin, "The Effect of Finishing and Polishing Systems on Surface Roughness, Microhardness and Microleakage of a Nanohybrid Composite," J. Int. Dent. Med. Res., vol. 5, no. 3, pp. 155-160, 2012, doi: 10.5167/uzh-73270.

[12] M. A. Chinelatti, D. T. Chimello, R. P. Ramos, and R. G. Palma-Dibb, "Evaluation of the surface hardness of composite resins before and after polishing at different times," J. Appl. Oral Sci., vol. 14, no. 3, pp. 188-192, 2006, doi: 10.1590/S1678-77572006000300008.

[13] B. J. Donova, S. Garoushi, L. Lassila, and P. Vallittu, "Oxygen inhibition layer of composite resins : effects of layer thickness and surface layer treatment on the interlayer bond strength," Eur J Oral Sci., vol. 123, no. 3, pp. 53-60, 2015, doi: 10.1111/eos.12167.

[14] M. D. Anggreani, Saryono, "Qualitative and Quantitative Methodology in the Health Research," Yogyakarta: Nuha Medika, 2017.

[15] S. Notoatmodjo, "Health Research Methodology," 3rd. Jakarta: PT Rineka Cipta, 2018.

[16] T. K. Hariprasath, S. Balaji Ganesh, and R. G. Devi, "Colour stability of composite resins-a review," Indian J. Forensic Med. Toxicol, vol. 14, no. 4, pp. 4673-4678, 2020, doi: 10.37506/ijfmt.v14i4.12374.

[17] A. A. Guler, E. Guler, A. Ç. Yucel, and E. Ertas, "Effects of polishing procedures on color stability of composite resins," J. Appl. Oral Sci, vol. 17, no. 2, pp. 108-112, 2009, doi: 10.1590/S1678-77572009000200007.

[18] U. Muhittin, T. U. Burak, and H. O. Kam, "Color stability of microhybrid and nanofilled composite resins: Effect of surface sealant agents containing different filler content," J. Contemp. Dent. Pract, vol. 20, no. 9, pp. 10451050, 2019, doi: 10.5005/jp-journals-10024-2636.

[19] A. Khatri and B. Nandlal, "Staining of a Conventional and a Nanofilled Composite Resin Exposed in vitro to Liquid Ingested by Children," Int. J. Clin. Pediatr. Dent., vol. 3, no. 3, pp. 183-188, 2010, doi: 10.5005/jpjournals-10005-1074i

[20] D. A. Terry and W. Geller, "Esthetic \& Restorative Dentistry Material Selection \& Technique," 2nd ed. Quintessence Publishing Co Inc, 2013.

[21] E. Takanashi et al., "Influence of abrasive particle size on surface properties of flowable composites," Dental Materials J., vol. 27, no. 6, pp. 780-786, 2008, doi: 10.4012/dmj.27.780.

[22] S. Jefferies, “Contemporary Esthetic Dentistry,” St.Louis : Elsevier mosby, 2012.

[23] G. Gulati and R. Hegde, "Comparative evaluation of two polishing systems on the surface texture of an aesthetic material (nano-composite): A profilometric study,” People J Sci Res., vol. 3, no. July, pp. 17-20, 2010.

[24] N. Gönülol and F. Yilmaz, "The effects of finishing and polishing techniques on surface roughness and color stability of nanocomposites," J. Dent., vol. 40, pp. 64-70, 2012, doi: 10.1016/j.jdent.2012.07.005.

[25] J. Janus, G. Fauxpoint, Y. Arntz, H. Pelletier, and O. Etienne, "Surface roughness and morphology of three nanocomposites after two different polishing treatments by a multitechnique approach," Dent. Mater., vol. 26, no. 5, pp. 416-425, 2010, doi: 10.1016/j.dental.2009.09.014.

[26] A. R. Yazici, D. Tuncer, S. Antonson, A. Onen, and E. Kilinc, "Effects of Delayed Finishing/Polishing on Surface Roughness, Hardness and Gloss of Tooth-Coloured Restorative Materials," Eur. J. Dent., vol. 04, no. 01, pp. 050056, 2010, doi: 10.1055/s-0039-1697808.

[27] P. M. Boroujeni et al., "The Effect of Finishing and Polishing Time on Microleakage of Composite Restorations," J. Islam. Dent. Assoc. IRAN, vol. 25, no. 3, pp. 272-277, 2013.

[28] M. U. Tangkudung and Trilaksana Aries Chandra, "Glycerin for resin composite restoration : Literature Review," Makassar Dent J., vol. 8, no. 3, pp. 169-172, 2019.

[29] L. L. Miotti, G. F. Nicoloso, L. B. Durand, A. H. Susin, and R. O. Rocha, "Color stability of a resin composite: Effect of the immersion method and surface treatments,” Indian J. Dent. Res., vol. 27, no. 2, pp. 195-199, 2016, doi: 10.4103/0970-9290.183137.

[30] J. Moon, S. Son, K. Jung, Y. Kwon, and J. Park, "Effect of immersion into solutions at various pH on the color stability of composite resins with different shades," Restor Dent Endod., vol. 40, no. 4, pp. 270-275, 2015, doi: 10.5395/rde.2015.40.4.270.

[31] S. Garoushi et al., "In fl uence of staining solutions and whitening procedures on discoloration of hybrid composite resins," Acta Odontol Scand., vol. 71, no. 1, pp. 144-150, 2013, doi: 10.3109/00016357.2011.654253.

[32] M. A. B. Da Silva, R. P. Vitti, M. A. C. Sinhoreti, R. L. X. Consani, J. G. Da Silva, and J. Tonholo, "Effect of alcoholic beverages on surface roughness and microhardness of dental composites," Dent. Mater. J., vol. 35, no. 4, pp. 621-626, 2016, doi: 10.4012/dmj.2015-383.

[33] E. M. Onyema, "Impact of Coronavirus Pandemic on Education," J. Educ. Pract., vol. 11, no. 13, pp. 108-121, 2020, doi: 10.7176/jep/11-13-12.

[34] P. Iyer, K. Aziz, and D. M. Ojcius, "Impact of COVID-19 on dental education in the United States," J. Dent. Educ., vol. 84, no. 6, pp. 718-722, 2020, doi: 10.1002/jdd.12163.

\section{APPENDIX}

Table 3. Respondent's answers

\begin{tabular}{lcc}
\hline \multicolumn{1}{c}{ Questions } & Respondent's answer & Percentage \\
\hline 1.The color stability of the composite resin restoration & & \\
Composite resin properties that tend to absorb color & 14 & $14 \%$ \\
Differences in the color of the composite resin restoration after use & 6 & $6 \%$
\end{tabular}

Int. J. Public Health Sci., Vol. 10, No. 4, December 2021 : 751 - 757 


\begin{tabular}{|c|c|c|}
\hline Questions & Respondent's answer & Percentag \\
\hline The ability of the composite resin to retain the initial color & 80 & $80 \%$ \\
\hline \multicolumn{3}{|c|}{ 2. Intrinsic factors that affect the color stability of the composite resin restoration } \\
\hline Fillers and diet & 17 & $17 \%$ \\
\hline Matrix and filler & 80 & $80 \%$ \\
\hline Inhibitors and the oral environment & 3 & $3 \%$ \\
\hline \multicolumn{3}{|l|}{ 3. Matrix monomer absorb the surrounding liquid } \\
\hline Hydrophobic & 16 & $16 \%$ \\
\hline Binds the filler & 29 & $29 \%$ \\
\hline Contains a hydroxyl group & 55 & $55 \%$ \\
\hline \multicolumn{3}{|l|}{ 4.Type of composite resin provides the best color stability } \\
\hline Nanocomposite resin & 83 & $83 \%$ \\
\hline Micro-hybrid composite resin & 14 & $14 \%$ \\
\hline Conventional composite resin & 3 & $3 \%$ \\
\hline \multicolumn{3}{|l|}{ 5. Effect of small filler on the composite resin restoration surface } \\
\hline Hard to polish & 6 & $6 \%$ \\
\hline Improve surface smoothness & 84 & $84 \%$ \\
\hline Lowering the density between particles & 10 & $10 \%$ \\
\hline \multicolumn{3}{|c|}{ 6. The surface of composite resin restoration with good color stability } \\
\hline Smooth & 91 & $91 \%$ \\
\hline Rough & 6 & $6 \%$ \\
\hline Hollow & 3 & $3 \%$ \\
\hline
\end{tabular}

7. The procedure that forms or reduces the restoration section in order to achieve the ideal shape

Finishing

$82 \quad 82 \%$

Polishing

$82 \%$
12
$12 \%$

Condensation

$6 \quad 6 \%$

8. The procedure allow a restoration to be smooth and glossy?

Carving

Polishing

Condensation

9. The stages in finishing

$\begin{array}{lll}\text { Shaping-Contouring-Prepolishing } & 78 & 78 \%\end{array}$

$\begin{array}{lll}\text { Prepolishing-Shaping-Contouring } & 78 & 17 \%\end{array}$

$\begin{array}{ll}\text { Contouring-Prepolishing-Shaping } & 5 \%\end{array}$

10. The effective instruments for finishing and polishing?

Diamond bur

Carbide bur

$16 \%$

Aluminum oxide coated abrasive discs

11. Polishing time to maintain the color stability of the composite resin restoration $\begin{array}{ll}\text { Immediately after restoration } & 31\end{array}$

$\begin{array}{ll}15 \text { minutes after restoration } & 17\end{array}$

24 hours after restoration

12. Effect of oxygen-inhibited layer on composite resin restoration

Evenly hardening of the material

Change the color of the restoration

Prevents edge leakage

13. The environment affect the color stability of the composite resin Low $\mathrm{pH}$

Degree of acidity of bases

14. Effect of colored drinks on the composite resin restoration

Lowered roughness

Interferes with color stability

$3 \quad 3 \%$

15. Alcohol affect the composite resin restoration surface

Adds to surface smoothness

$11 \%$

Reduces cavities on the surface

Increase surface roughness

$\begin{array}{ll}18 & 18 \% \\ 71 & 71 \%\end{array}$

